\title{
Clinical evaluation of two materials in the restoration of abfraction lesions
}

\author{
Fabianna da Conceição Dantas de Medeiros ${ }^{1}$, Marquiony Marques Santos ${ }^{1}$, Isaac Jordão de Souza Araújo², \\ Isabela Pinheiro Cavalcanti Lima²
}

\author{
${ }^{1}$ Universidade Estadual do Rio Grande do Norte - UERN, Department of Dentistry, Area of Dental Materials, Caicó, RN, Brazil \\ ¿Universidade Estadual de Campinas - UNICAMP, Piracicaba Dental School, Area of Dental Materials, Piracicaba, SP, Brazil
}

\begin{abstract}
Aim: To evaluate the clinical performance of a composite resin (CR) and a resin-modified glassionomer cement (RMGIC) for the treatment of abfraction lesions. Methods: Thirty patients with abfraction lesions in at least two premolar teeth were selected and invited to participate in this study. All restorations were made within the same clinical time frame. One tooth was restored with $\mathrm{CR} Z 100^{\mathrm{TM}}$ (3M, St. Paul, MN, USA), and the other was restored with RMGIC Vitremer ${ }^{\mathrm{TM}}(3 \mathrm{M})$. The restorations were assessed immediately and 1, 6 and 12 months after the restoration, using modified US Public Health Service (USPHS) criteria: marginal integrity, marginal discoloration, wear, retention, secondary caries and hypersensitivity. The statistical analysis was based on Friedman ANOVA test and Mann-Whitney test, considering $p<0.05$ for statistical significance. Results: Both materials demonstrated satisfactory clinical performance after one year. In the individual analysis of each material, there was a significant difference $(p<0.05)$ in the criteria marginal integrity and wear, for both CR and RMGIC. RMGIC exhibited more damage one year after the restoration. Comparing both materials, it was found a significant difference only for marginal discoloration, while the RMGIC restorations showed the worst prognosis after a year of evaluation. There was no significant difference in the number of retentions, caries or hypersensitivity between CR and RMGIC. Conclusions: It was concluded that CR exhibited the best clinical performance according to the cost-effectiveness and evaluation criteria used in this study.
\end{abstract}

Keywords: composite resins; glass ionomer cements; tooth wear.

\section{Introduction}

Received for publication: November 04, 2015 Accepted: December 12, 2015

Correspondence to: Fabianna da Conceição Dantas de Medeiros Departament of Dentistry Caicó Campus, UERN Rua André Sales, 667, Paulo VI, CEP 59300-000 Caicó,

Rio Grande do Norte, Brasil Phone: +55 8434216513

E-mail: fabianna.89@hotmail.com
Abfraction is a concept that explains the pathological loss of cervical tooth structure caused by eccentric occlusal forces on the teeth ${ }^{1-2}$. Problems such as dentinal hypersensitivity, increased bacterial biofilm retention and caries incidence are commonly related to abfraction lesions and require the replacement of the lost tooth tissue with restorative materials ${ }^{3}$.

The treatment of abfraction lesions depends on the elimination of the etiological factors, and it is done by a combination of preventive and therapeutic measures. In addition, performing occlusal adjustment prior to restoration is of paramount importance for a successful treatment ${ }^{4}$. Commonly used restorative materials are composite resin (CRs), glass-ionomer cement or a combination of both materials and their appropriate adhesive systems. The dentist's choice of the restorative material is usually determined by factors such as micromechanical adhesive retention, tooth structure preservation, and good aesthetic and functional outcomes 5 .

However, several studies report failure of cervical restorations of abfraction lesions and an incessant search for the most suitable restorative material ${ }^{4,6-8}$. 
Therefore, this study aimed to evaluate the clinical performance of a CR compared with a resin-modified glass-ionomer cement (RMGIC) in the treatment of abfraction lesions.

\section{Material and methods}

\section{Study design and sample}

This study involved the clinical follow up of patients treated at the integrated dentistry clinic at Universidade Estadual do Rio Grande do Norte (UERN), Caicó, RN, Brazil. The volunteers $(n=30)$ who participated in this clinical trial were 18-50 years old. All participants were informed about the conditions and goals of this study and signed a written informed consent. The study project has been previously reviewed and approved by the local Research Ethics Committee (Process No. 785.023 / 2014).

The sample size was determined considering a retention rate of $98 \%$ for RMGIC after one year ${ }^{9}$ and a unilateral test with an alpha level of 5\% and a power of $80 \%$. Thus, in order to detect a difference of $20 \%$, the minimum sample size was set at 30 volunteers.

Each volunteer received two restorations of abfraction lesions, totaling 60 dental restorations. All procedures were performed in accordance with the recommendations of the American Dental Association (ADA) for clinical trials with restorative materials ${ }^{10}$.

The criteria for participation were good general health, current treatment at the dentistry clinic at UERN, satisfactory oral hygiene and acceptable oral conditions. The required occlusal restorations were already placed on all posterior teeth except those with abfraction lesions. Additionally, in order to participate in the study, volunteers were required to have at least 20 teeth and one abfraction lesion in two different premolar teeth, in contact with antagonist teeth.

All premolars presented wedge-shaped cervical lesions with e" $1 \mathrm{~mm}$ depth on the vestibular sides. Volunteers were excluded from the study if they required dental prostheses in the spaces contiguous to target teeth, a diagnosis of caries coincident with the cervical lesion, or an indication for irreversible endodontic treatment of the target teeth. Other exclusion criteria were the existence of moderate-to-severe periodontal damage and/or parafunctional habits. Patients selected for the study were already under treatment in the Integrated Dental Clinics, including those forwarded and screened in the Temporomandibular Disorders Extension Project, which excluded patients with severe occlusal problems and more severe parafunctional habits, avoiding bias in the study.

The methodology was based on the split-mouth system. For standardization purposes, the tooth pairs chosen for restoration had to be similar in size and depth. A premolar from each dental arch, located in different hemi-arches was selected.

\section{Clinical protocol of the restoration}

For standardization purposes, the same researcher and his/her assistant performed all restorative procedures. Each patient received two restorations: one with $\mathrm{CR} Z 100^{\mathrm{TM}}(3 \mathrm{M}$,
St. Paul, MN, USA) and the other with RMGIC Vitremer ${ }^{\mathrm{TM}}$ (3M, St. Paul, MN, USA). The restorative materials were randomly assigned to patients, through a simple lottery. Prior to restoration, all patients underwent complete occlusal adjustment via selective grinding.

All restorations were carried out with rubber dam isolation without cavity preparation, apart from prophylaxis and cleaning of the walls to be restored with pumice paste and water. The materials were handled and inserted according to the manufacturers' recommendations.

For CR restorations the acid etching was made with $37 \%$ phosphoric acid (Dentscare, Joinville, SC, Brazil) for $30 \mathrm{~s}$, followed by rinsing for $30 \mathrm{~s}$ and drying with an air syringe for $15 \mathrm{~s}$. The adhesive Adper Single Bond ${ }^{\mathrm{TM}}$ (3M ESPE, St. Paul, MN, USA) was applied using a microbrush compatible with the abfraction size, light cured with a conventional lightcuring unit (Elipar Free Light, 3M ESPE) emitting at 1200 $\mathrm{mW} / \mathrm{cm}^{2}$ for $20 \mathrm{~s}$. Z100 CR (3M ESPE) was inserted according to an incremental technique in increments not thicker than $2.0 \mathrm{~mm}$ light cured with the same light-curing unit (Elipar Free Light) for $40 \mathrm{~s}$ at each increment.

In RMGIC restorations, the primer from kit Vitremer ${ }^{\mathrm{TM}}$ (3M ESPE) was applied with a microbush on the surface of the abfraction, left for $30 \mathrm{~s}$ and light cured with Elipar Free Light $1200 \mathrm{~mW} / \mathrm{cm}^{2}$ for $20 \mathrm{~s}$. RMGIC was prepared considering a powder/liquid ratio $1: 1$ by agglutination for approximately $45 \mathrm{~s}$ until a moist and shiny mass with creamy consistency was obtained. The material was inserted into the abfraction in 2.0-mm-thick increments light cured with the same light-curing unit (Elipar Free Light) for $40 \mathrm{~s}$ at each increment.

After the restorations with both materials, the gross excesses were removed and initial finishing was performed. In the following session, finishing and polishing were completed using composite polishing burs and rubber tips.

\section{Clinical Evaluation - Data Collection}

Two calibrated and trained dentists blinded to the materials and methodology of the study evaluated the restorations. The study's coordinator conducted calibration of the evaluators. The clinical parameters were explained and a trial data collection with the equivalent of $10 \%$ of the sample was performed. Kappa Cohen test was applied to confirm the calibration of the evaluators and satisfactory results were obtained $(\mathrm{Kappa}=0.85)$. The examiners evaluated all restorations by filling out an individual record sheet for each patient. These records were made using the following modified USPHS criteria ${ }^{11}$ : marginal integrity, marginal discoloration, wear, retention, secondary caries and hypersensitivity (Table 1). The restorations were assessed immediately, one, six and twelve months after placement.

\section{Statistical Analysis}

In order to investigate the relationship between the dependent (marginal integrity, marginal discoloration, wear, retention, secondary caries, and hypersensitivity) and the independent variables (time gap of evaluations, materials - 
Table 1 - Description of the criteria used for the clinical evaluation of restorations.

\begin{tabular}{|c|c|c|}
\hline Criteria & Score & Description of the criteria \\
\hline \multirow[t]{3}{*}{ Marginal integrity } & Alfa (A) & There is no visual evidence of marginal fracture in the interface tooth/restoration. \\
\hline & Bravo (B) & There are visible and tactile evidence of the presence of cleft, but the dentin is not exposed. \\
\hline & Charlie (C) & The explorer penetrates the tooth/restoration interface, with exposed dentin. \\
\hline \multirow[t]{3}{*}{ Wear } & Alfa (A) & The restoration has continuity with the anatomical shape of the existing tooth. \\
\hline & Bravo (B) & The restoration has continuity with the anatomical, but no has dentin exposure. \\
\hline & Charlie (C) & There is loss of restorative material leading to dentin exposure \\
\hline \multirow[t]{3}{*}{ Marginal discoloration } & Alfa $(A)$ & There is no visual evidence of marginal discoloration on the tooth/restoration interface. \\
\hline & Bravo (B) & There is visual evidence of marginal discoloration on the tooth interface/restoration. \\
\hline & Charlie (C) & There is visual evidence of marginal discoloration, with extent of penetration in the pulp. \\
\hline \multirow[t]{2}{*}{ Retention } & Alfa $(A)$ & Presence of restoration. \\
\hline & Charlie (C) & Partial absence or total restoration. \\
\hline \multirow[t]{2}{*}{ Recurrent caries } & Alfa $(A)$ & There is no visual evidence of decay in the tooth/restoration interface. \\
\hline & Charlie (C) & There is visual evidence of decay in the tooth/restoration interface. \\
\hline \multirow[t]{3}{*}{ Post operative Sensitivity } & Alfa $(A)$ & Painful symptoms of absence to thermal stimuli and / or percussion. \\
\hline & Bravo (B) & Presence of painful symptoms when the performance of the different stimuli. \\
\hline & Charlie (C) & Presence of spontaneous symptoms reported by the patient. \\
\hline
\end{tabular}

Reference: Santiago et al (2010)12.

CR or RMGIC) the following non-parametric tests were used: Friedman's ANOVA, the Wilcoxon post-hoc test and the Mann-Whitney test. All tests were performed using SPSS version 20.0 (SPSS Inc., Chicago, USA). The level of significance was set to $5 \%(\mathrm{p}<0.05)$.

\section{Results}

Four patients were lost at the last follow-up interval - 1 year. This loss is equivalent to eight restorations, which did not affect the comparison of results.

Table 2 summarizes the average results of the criteria used for assessing CR restorations immediately, one month, six months and one year after placement. Among the analyzed criteria, there were significant changes $(p<0.05)$ in marginal integrity and wear after 6 months and one year post-placement, respectively. Although there were significant changes in marginal discoloration $(\mathrm{p}<0.05)$, no significant difference $(p>0.05)$ was found between the evaluation periods times.

Table 3 summarizes the average results of the criteria used for assessing RMGIC restorations immediately, one, six and twelve months after placement. According to Table 3, there were statistically significant changes $(p<0.05)$ in marginal integrity and wear of RMGIC restorations. There were statistically significant changes $(p<0.05)$ in marginal integrity of RMGIC restorations after six months and one year. There were also significant changes $(p<0.05)$ in the wear of restorations at one year post-placement. RMGIC restorations showed marginal discoloration at six months post-placement.

For both materials, in the individual evaluation, no significant differences $(p>0.05)$ were observed over time criteria for secondary caries, hypersensitivity and retention, as shown in Tables 2 and 3.

Table 4 shows the comparison of the mean for CR and RMGIC over the evaluated intervals. Except for marginal discoloration after one year of evaluation, there were no significant differences $(p>0.05)$ between both materials for all evaluated criteria.

\section{Discussion}

In general, the multifactorial etiology, pathogenesis, diagnosis and selection of procedures for the restoration of abfraction lesions have challenged modern dentistry and generated a good deal of discussion.

The findings of this study are in line with the study by Santiago et al. (2010) ${ }^{12}$, who found no significant difference in marginal integrity and wear for CR at one year postplacement. The flaws identified in the marginal integrity of the $\mathrm{CR}$ restorations after six months may be due to failures in the interface between the tooth and the restorative material, especially near the cavosurface angle of the abfraction lesions. Moreover, the tooth is subjected to occlusal loads with time $e^{3,13}$.

The poor marginal fit of CR restorations denotes adhesive bond degradation and polymerization shrinkage, which is a difference from the thermal expansion coefficient between the material/tooth and the occlusal loads ${ }^{14-15}$. The high modulus of elasticity of micro-hybrid CRs (e.g. Z100) characterizes them as rigid materials. This means that if subjected to occlusal load, they are unable to flex along with the tooth ${ }^{15-16}$. In their in vitro study, Pereira et al. (2012) ${ }^{8}$ 
Table 2 - Comparison of the average results obtained for the USPHS criteria used for assessing CR restorations immediately, one month, six months and one year after placement

\begin{tabular}{|c|c|c|c|c|}
\hline Variable & Times & Average & $\mathrm{DP} \pm$ & $p$ \\
\hline \multirow[t]{4}{*}{ Marginal integrity } & Immediately a & 2.84 & 0.37 & 0.001 \\
\hline & 1 month a,b & 2.72 & 0.46 & \\
\hline & 6 months $^{b}$ & 2.60 & 0.50 & \\
\hline & 1 year ${ }^{b}$ & 2.52 & 0.59 & \\
\hline \multirow[t]{4}{*}{ Wear } & Immediately a & 2.84 & 0.37 & 0.021 \\
\hline & 1 month a,b & 2.80 & 0.41 & \\
\hline & 6 months $a, b$ & 2.72 & 0.46 & \\
\hline & 1 year $^{b}$ & 2.60 & 0.50 & \\
\hline \multirow[t]{4}{*}{ Marginal discoloration } & Immediately a & 2.92 & 0.28 & 0.083 \\
\hline & 1 month a & 2.80 & 0.41 & \\
\hline & 6 months $^{\text {a }}$ & 2.76 & 0.44 & \\
\hline & 1 year $^{a}$ & 2.88 & 0.33 & \\
\hline \multirow[t]{4}{*}{ Retention } & Immediately a & 2.96 & 0.20 & 0.234 \\
\hline & 1 month a & 2.92 & 0.28 & \\
\hline & 6 months $^{\text {a }}$ & 2.84 & 0.37 & \\
\hline & 1 year $^{a}$ & 2.76 & 0.60 & \\
\hline \multirow[t]{4}{*}{ Recurrent caries } & Immediately a & 3.00 & 0.00 & 1.000 \\
\hline & 1 month a & 3.00 & 0.00 & \\
\hline & 6 months $^{\text {a }}$ & 3.00 & 0.00 & \\
\hline & 1 year ${ }^{a}$ & 3.00 & 0.00 & \\
\hline \multirow[t]{4}{*}{ Sensitivity } & Immediately a & 2.88 & 0.33 & 0.954 \\
\hline & 1 month a & 2.88 & 0.33 & \\
\hline & 6 months ${ }^{a}$ & 2.84 & 0.37 & \\
\hline & 1 year a $^{2}$ & 2.88 & 0.33 & \\
\hline
\end{tabular}

Table 3 - Comparison of the average results obtained for the USPHS criteria used for assessing RMGIC restorations immediately, one month, six months and one year after placement

\begin{tabular}{|c|c|c|c|c|}
\hline Variable & Times & Average & $\mathrm{DP} \pm$ & $p$ \\
\hline \multirow[t]{4}{*}{ Marginal integrity } & Immediately ${ }^{a}$ & 2.88 & 0.44 & 0.001 \\
\hline & 1 month a,c & 2.80 & 0.58 & \\
\hline & 6 months $^{b}$ & 2.56 & 0.65 & \\
\hline & 1 year $^{b, c}$ & 2.44 & 0.71 & \\
\hline \multirow[t]{4}{*}{ Wear } & Immediately a & 2.88 & 0.33 & 0.001 \\
\hline & 1 month a & 2.88 & 0.33 & \\
\hline & 6 months $a, b$ & 2.68 & 0.56 & \\
\hline & 1 year $^{b}$ & 2.40 & 0.76 & \\
\hline \multirow[t]{4}{*}{ Marginal discoloration } & Immediately a & 2.88 & 0.33 & 0.018 \\
\hline & 1 month $a, b$ & 2.84 & 0.37 & \\
\hline & 6 months $^{b}$ & 2.72 & 0.46 & \\
\hline & 1 year $^{b}$ & 2.64 & 0.49 & \\
\hline \multirow[t]{4}{*}{ Retention } & Immediately a & 2.96 & 0.20 & 0.194 \\
\hline & 1 month a & 2.92 & 0.40 & \\
\hline & 6 months ${ }^{a}$ & 2.84 & 0.47 & \\
\hline & 1 year $^{a}$ & 2.64 & 0.76 & \\
\hline \multirow[t]{4}{*}{ Recurrent caries } & Immediately a & 3.00 & 0.00 & 1.000 \\
\hline & 1 month a & 3.00 & 0.00 & \\
\hline & 6 months $^{a}$ & 3.00 & 0.00 & \\
\hline & 1 year a & 3.00 & 0.00 & \\
\hline \multirow[t]{4}{*}{ Sensitivity } & Immediately a & 2.92 & 0.28 & 0.274 \\
\hline & 1 month ${ }^{a}$ & 2.88 & 0.33 & \\
\hline & 6 months $^{\text {a }}$ & 2.80 & 0.41 & \\
\hline & 1 year a & 2.96 & 0.20 & \\
\hline
\end{tabular}


Table 4 - Comparison of the average results obtained for RMGIC e CR restorations immediately, one month, six months and one year after placement.

\begin{tabular}{|c|c|c|c|c|}
\hline Variable & Materials & Average & $\mathrm{DP} \pm$ & $\mathrm{p}$ \\
\hline \multirow[t]{2}{*}{ Marginal integrity Immediately } & $\mathrm{CR}$ & 2.84 & 0.37 & 0.490 \\
\hline & RMGIC & 2.88 & 0.44 & \\
\hline \multirow[t]{2}{*}{ Marginal integrity 1 month } & $\mathrm{CR}$ & 2.72 & 0.46 & 0.269 \\
\hline & RMGIC & 2.80 & 0.58 & \\
\hline \multirow[t]{2}{*}{ Marginal integrity 6 months } & $\mathrm{CR}$ & 2.60 & 0.50 & 0.964 \\
\hline & RMGIC & 2.56 & 0.65 & \\
\hline \multirow[t]{2}{*}{ Marginal integrity 1 year } & $\mathrm{CR}$ & 2.52 & 0.59 & 0.809 \\
\hline & RMGIC & 2.44 & 0.71 & \\
\hline \multirow[t]{2}{*}{ Wear Immediately } & $\mathrm{CR}$ & 2.84 & 0.37 & 0.720 \\
\hline & RMGIC & 2.88 & 0.33 & \\
\hline \multirow[t]{2}{*}{ Wear 1 month } & $\mathrm{CR}$ & 2.80 & 0.41 & 0.492 \\
\hline & RMGIC & 2.88 & 0.33 & \\
\hline \multirow[t]{2}{*}{ Wear 6 months } & $\mathrm{CR}$ & 2.72 & 0.46 & 0.931 \\
\hline & RMGIC & 2.68 & 0.56 & \\
\hline \multirow[t]{2}{*}{ Wear 1 year } & $\mathrm{CR}$ & 2.60 & 0.50 & 0.471 \\
\hline & RMGIC & 2.40 & 0.76 & \\
\hline \multirow[t]{2}{*}{ Marginal discoloration Immediately } & $\mathrm{CR}$ & 2.92 & 0.28 & 0.393 \\
\hline & RMGIC & 2.88 & 0.33 & \\
\hline \multirow[t]{2}{*}{ Marginal discoloration 1 month } & $\mathrm{CR}$ & 2.80 & 0.41 & 0.741 \\
\hline & RMGIC & 2.84 & 0.37 & \\
\hline \multirow[t]{2}{*}{ Marginal discoloration 6 months } & $\mathrm{CR}$ & 2.76 & 0.44 & 0.372 \\
\hline & RMGIC & 2.72 & 0.46 & \\
\hline \multirow[t]{2}{*}{ Marginal discoloration 1 year } & $\mathrm{CR}$ & 2.88 & 0.33 & 0.049 \\
\hline & RMGIC & 2.64 & 0.49 & \\
\hline \multirow[t]{2}{*}{ Retention Immediately } & $\mathrm{CR}$ & 2.96 & 0.20 & 1.000 \\
\hline & RMGIC & 2.96 & 0.20 & \\
\hline \multirow[t]{2}{*}{ Retention 1 month } & CR & 2.92 & 0.28 & 0.584 \\
\hline & RMGIC & 2.92 & 0.40 & \\
\hline \multirow[t]{2}{*}{ Retention 6 months } & $\mathrm{CR}$ & 2.84 & 0.37 & 0.953 \\
\hline & RMGIC & 2.84 & 0.47 & \\
\hline \multirow[t]{2}{*}{ Retention 1 year } & CR & 2.76 & 0.60 & 0.653 \\
\hline & RMGIC & 2.64 & 0.76 & \\
\hline \multirow[t]{2}{*}{ Caries Immediately } & $\mathrm{CR}$ & 3.00 & 0.33 & 1.000 \\
\hline & RMGIC & 3.00 & 0.28 & \\
\hline \multirow[t]{2}{*}{ Caries 1 month } & CR & 3.00 & 0.00 & 1.000 \\
\hline & RMGIC & 3.00 & 0.00 & \\
\hline \multirow[t]{2}{*}{ Caries 6 months } & $\mathrm{CR}$ & 3.00 & 0.00 & 1.000 \\
\hline & RMGIC & 3.00 & 0.00 & \\
\hline \multirow[t]{2}{*}{ Caries 1 year } & CR & 3.00 & 0.00 & 1.000 \\
\hline & RMGIC & 3.00 & 0.00 & \\
\hline \multirow[t]{2}{*}{ Hypersensitivity Immediately } & $\mathrm{CR}$ & 2.88 & 0.33 & 0.393 \\
\hline & RMGIC & 2.92 & 0.28 & \\
\hline \multirow[t]{2}{*}{ Hypersensitivity 1 month } & CR & 2.88 & 0.33 & 0.451 \\
\hline & RMGIC & 2.88 & 0.33 & \\
\hline Hypersensitivity 6 months & $\mathrm{CR}$ & 2.84 & 0.37 & 0.740 \\
\hline & RMGIC & 2.80 & 0.41 & \\
\hline Hypersensitivity 1 year & $\mathrm{CR}$ & 2.88 & 0.33 & 0.302 \\
\hline & RMGIC & 2.96 & 0.20 & \\
\hline
\end{tabular}

found changes in the marginal integrity of teeth restored with Z100 resin. The high modulus of elasticity of this resin is insufficient to dissipate the stress of polymerization shrinkage. This is a persistent feature CRs, which ultimately leads to adhesion failure and seal collapse. Awliya and ElSahn $(2008)^{17}$ showed that the Class-V lesions restored with high-elasticity resins exhibited a satisfactory distribution of stresses, without marginal deterioration. 
In line with the findings of other studies ${ }^{9,12,18}$, we found unsatisfactory marginal integrity results for RMGIC restorations. In contrast, other studies found that a RMGIC (Vitremer) was the best material for keeping the integrity at the dentin edge ${ }^{8,18}$. Despite the favorable biomechanical characteristics of RMGIC, the striking marginal deterioration of RMGIC restorations may result from the hygroscopic expansion of glass ionomer components and fractures due to excessive contouring of the edges by materials subjected to occlusal loads ${ }^{19}$.

Although finishing or beveling of the enamel walls has not yet been performed, the very configuration of lesion may lead to the occurrence of abfracted, friable, and unsupported enamel edges that surpass the cavosurface angle ${ }^{20}$. Thus, minor marginal fractures are associated with the small volume of RMGIC in the interface between tooth and restoration.

When there is a satisfactory bond between the restorative material and the tooth, the forces generated by the compression of the restoration will act more upon the body than on the adhesive interface. As a consequence, the adhesive bond will be preserved. This will allow favorable retention of the restoration even if the marginal integrity is affected $^{8,18}$, as shown in this study.

According to Van Landuyt et al. (2011) ${ }^{21}$, although the retention rates for current adhesive systems have improved, marginal sealing remains problematic. Analogous to this research, Burrow (2011) $)^{22}$ also found that marginal deterioration was more outstanding than discoloration for both materials. However, this marginal deterioration did not compromise the overall performance of the restorations ${ }^{23}$, because both restorations were considered clinically acceptable and did not have to be replaced.

Marginal discoloration is expected following damage to the edges of the restoration. In the initial assessments in this study, the statistical analysis revealed some change in the color of the edges for both study materials. This may relate to difficulties with the finishing and polishing of the cervical restorations. It may also relate to the excess of restorative material (not removed after polishing) in nonconditioned areas, as this facilitates the impregnation of pigments $^{24}$.

The initial color stability of RMGIC is generally satisfactory. It has ben demonstrated, however, that this material tends to change its color over times. This may be related to surface changes within the material, as indicated by loss of anatomic contour and wear. This was also evident in the results of the present study.

In agreement with other studies ${ }^{6,9,12,22}$, the present investigatiin found a significant difference in wear of both materials after one year of placement, mainly in CR. Santiago et al. (2010) $)^{12}$ observed significant differences over time in the anatomical shape of the materials, especially $\mathrm{CR}$, as compared to glass-ionomer cement. A possible explanation for the wear of $\mathrm{CR}$ restorations may be that the tensile stress during tooth bending would favor the formation of cracks in the body of the restoration, facilitating the detachment of inorganic resin fillers when they are subjected to conditions of mechanical friction and chemical abrasion, as during toothbrushing ${ }^{14}$.

The long-term anatomical wear of glass-ionomer restorations may be attributed to inferior physical properties ${ }^{25}$ relative to $\mathrm{CR}$. Glass-ionomer has low resistance to the wear ${ }^{26}$ associated with excessive brushing force. Van Dijken and Pallesen (2008) ${ }^{27}$, however, found that Vitremer was able to satisfactorily maintain its anatomical shape, which may be due to the improved physical properties of hybrid ionomer restorative materials.

Glass-ionomer cements tend to incorporate air bubbles during handling. The air bubbles and filler particles (which become exposed following brushing) result in porosities, increased roughness and wear ${ }^{8}$. These effects can be observed clinically.

The secondary caries criterion remained unchanged for both materials throughout the evaluation period. Similarly, no statistically significant difference was observed for postoperative hypersensitivity. In agreement with these findings, Pollington and Van Noort $(2008)^{28}$ found that out of the $60 \mathrm{CR}$ restorations placed during their study, none showed signs of caries or postoperative hypersensitivity.

In this study, however, some patients exhibited hypersensitivity immediately and one month after restoration. The hypersensitivity experienced immediately after restoration may result from mechanical damage to the gums. This may occur during the finishing and polishing of the restorative materials or when excess material remains in contact with the soft tissue ${ }^{29}$.

Gingival recession and root exposure immediately after placement or following finishing and polishing have been associated with tooth hypersensitivity in one-month postrestoration $^{30}$. This was also observed by Stojanac et al. $(2013)^{14}$. In their study, the hypersensitivity measured in the initial assessment decreased over time and disappeared completely after two years.

Several similar studies found no secondary caries associated with cervical restorations $\mathrm{s}^{9,12,14,29-30}$. The absence of caries in the assessed restorations may be due because the participants were undergoing oral treatment (in the phase after conditioning of the oral environment) and maintained satisfactory oral hygiene. Moreover, the evolution in GIC has contributed to the reduction of dental caries because of its characteristics ${ }^{31-32}$.

Based on the findings of this study, both materials provided satisfactory clinical performance in the restoration of cervical abfraction lesions, with peculiarities inherent to the physicochemical properties of each one of them. Nevertheless, cost-effectiveness should be considered when choosing a restorative material. RMGIC is more expensive than CR. The authors believe that understanding the biomechanics of cervical restorations makes the selection of restorative materials easier and enables a better prognosis. This is due to a broader understanding of all associated factors.

In conclusion, the composite can be a good option to restore abfraction lesions. The use of this material or RMGIC should be inexorably bound to the balance of the occlusal 
load, in order to increase the longevity of the restoration and preserve the remaining tooth structure. Given the limitations of this study, further research into the treatment of abfraction lesions is recommended. Future studies should employ indirect review methods and functional analysis of occlusion.

\section{References}

1. Grippo JO, Simring M, Coleman TA. Abfraction, abrasion, biocorrosion, and the enigma of noncarious cervical lesions: a 20-year perspective. J Esthet Restor Dent. 2012; 24: 10-23.

2. Marcauteanu C, Adrian B, Cosmin S, Florin IT, Meda LN, Adrian GP. Quantitative evaluation of dental abfraction and attrition using a sweptsource optical coherence tomography system. J Biomed Opt. 2014; 19: 21108.

3. Soares P, Milito GA, Pereira FA, Zeola LF, Naves MFL, Faria VLG, et al. Non carious cervical lesions: influence of morphology and load type on biomechanical behaviour of maxillary incisors. Aust Dent J. 2013; 58 : 306-14.

4. Schindler HJ, Turp JC. Meticulous occlusal adjustment aimed at elimination of all occlusal interferences. Eur J Orthod. 2010; 32: 228-9.

5. Huangfu RQ, Xu X. Restoration of non-carious cervical lesions in the first maxillary premolar: a three dimentional finite element study. Shanghai Kou Qiang Yi Xue. 2011; 20: 26-30.

6. Kim SY, Lee KW, Seong SR, Lee MA, Oh MH, Cho BH. Two-year clinical effectiveness of adhesives and retention form on resin composite restorations of non-carious cervical lesions. Oper Dent. 2009; 34: 507-15.

7. Pecie R, Krejci I, García-Godoy F, Bortolotto T. Noncarious cervical lesions (NCCL) - a clinical concept based on the literature review. Part 2: Restoration. Am J Dent. 2011; 24: 183-92.

8. Pereira AFV, Poiate IAVP, Poiate EJ, Rodrigues FP, Turbino ML, Miranda WGJ. Influence of restorative techniques on marginal adaptation and dye penetration around Class V restorations. Gen Dent. 2012;60: 17-21.

9. Sidhu SK. Clinical evaluations of resin-modified glass-ionomer restorations. Dent Mater. 2010; 26: 7-12.

10. American Dental Association. Council on scientific affairs. Restorative Materials; 2001. In: Loguercio AD, Raffo J, Bassani F, Balestrini H, Santo $D$, do Amaral RC, et al. 24-month clinical evaluation in non-carious cervical lesions of a two-step etch-and-rinse adhesive applied using a rubbing motion. Clin Oral Investig. 2011; 15: 589-96.

11. Bayne SC, Schmalz G. Reprinting the classic article on USPHS evaluation methods for measuring the clinical research performance of restorative materials. Clin Oral Investig. 2005; 9: 209-14.

12. Santiago SL, Passos VF, Vieira AHM, Navarro MFL, Lauris JRP, Franco EB. Two-year clinical evaluation of resinous restorative systems in noncarious cervical lesions. Braz Dent J. 2010; 21: 229-34.

13. Brandini DA, Trevisan CL, Barioni SRP, Pedrini D. Clinical evaluation of the association between noncarious cervical lesions and occlusal forces. J Prosthet Dent. 2012; 108: 298-303.

14. Stojanac IL, Premovic MT, Ramic BD, Drobac MR, Stojsin IM, Petrovic LM. Noncarious cervical lesions restored with three different tooth-colored materials: two-year results. Oper Dent. 2013; 38: 12-20.

15. Petrovic LM, Drobac MR, Stojanac IL. A method of improving marginal adaptation by elimination of singular stress point in composite restorations during resin photo-polymerization. Dent Mater. 2010, 26: 449-55.

16. Kubo S, Yokota $\mathrm{H}$, Hayashi $Y$. Three-year clinical evaluation of a flowable and a hybrid resin composite in non-carious cervical lesions. J Dent. 2010; 38: 191-200.

17. Awliya WY, El-Sahn AM. Leakage pathway of Class $V$ cavities restored with different flowable resin composite restorations. Oper Dent. 2008; 33: 31-6.
18. Francisconi LF, Scaffa PMC, Barros VR, Coutinho M, Francisconi PA. Glass ionomer cements and their role in the restoration of non-carious cervical lesions. J Appl Oral Sci. 2009; 17: 364-9.

19. Santamaria MP, da Silva Feitosa D, Nociti Jr FH, Casati MZ, Sallum AW, Sallum EA. Connective tissue graft plus resin-modified glass ionomer restoration for the treatment of gingival recession associated with noncarious cervical lesion: a randomized-controlled clinical trial. J Clin Periodontol. 2009; 36: 791-8.

20. Baig MM, Mustafa M, Jeaidi ZAA, Al-Muhaiza M. Microleakage evaluation in restorations using different resin composite insertion techniques and liners in preparations with high c-factor -An in vitro study. King Saud Univ J Dent Sci. 2013; 4: 57-64.

21. Van Landuyt KL, Peumans M, De Munck J, Cardoso MV, Ermis B, Van Meerbeek $B$. Three-year clinical performance of a HEMA-free one-step self-etch adhesive in non-carious cervical lesions. Eur J Oral Sci. 2011 119: 511-6.

22. Burrow MF. Clinical evaluation of non-carious cervical lesion restorations using a HEMA-free adhesive: three-year results. Aust Dent J. 2011; 56: 401-5.

23. Chee B, Rickman LJ, Satterthwaite JD. Adhesives for the restoration of non-carious cervical lesions: a systematic review. J Dent. 2012; 40: 44352.

24. Heintze SD, Thunpithayakul C, Armstrong SR, Rousson V. Correlation between microtensile bond strength data and clinical outcome of Class $\mathrm{V}$ restorations. Dent Mater. 2011; 27: 114-25.

25. Lund RG, Ogliari F, Lima GS, Del-Pino FAB, Petzhold CL, Piva E. Diametral tensile strength of two Brazilian resin-modified glass ionomers cements: influence of the powder/liquid ratio. Braz J Oral Sci. 2007; 6: 1353-6.

26. Torabzadeh H, Ghasemi A, Shakeri S, Baghban AA, Razmavar S. Effect of powder/liquid ratio of glass ionomer cements on flexural and shear bond strengths to dentin. Braz J Oral Sci. 2011; 10: 204-7.

27. Van Dijken JW, Pallesen U. Long-term dentin retention of etch-and-rinse and self-etch adhesives and a resin-modified glass ionomer cement in noncarious cervical lesions. Dent Mater. 2008; 24: 915-22.

28. Pollington $S$, Van Noort R. A clinical evaluation of a resin composite and a compomer in non-carious Class V lesions. A3-year follow-up. Am J Dent. 2008; 21: 49-52.

29. Veitz-Keenan A, Barna JA, Strober B, Matthews AG, Collie D, Vena D, et al. Treatments for hypersensitive noncarious cervical lesions: a Practitioners Engaged in Applied Research and Learning (PEARL) Network randomized clinical effectiveness study. J Am Dent Assoc. 2013; 144: 495-506.

30. Loguercio AD, Raffo J, Bassani F, Balestrini $H$, Santo D, do Amaral RC, et al. 24-month clinical evaluation in non-carious cervical lesions of a twostep etch-and-rinse adhesive applied using a rubbing motion. Clin Oral Investig. 2011; 15: 589-96.

31. Pithon MM, Ruellas ACO, Sant'anna EF. Effect of bleaching with hydrogen peroxide into different concentrations on shear strength of brackets bonded with a resin-modified glass ionomer. Braz J Oral Sci. 2008; 7: 1483-8.

32. Graciano KP, Moysés MR, Ribeiro JC, Pazzini CA, Melgaço CA, Ramos-Jorge J. One-year clinical evaluation of the retention of resin and glass ionomer sealants on permanent first molars in children. Braz J Oral Sci. 2015; 14: 190-4 